\title{
Populações racializadas: um ensaio teórico sobre construção da memória coletiva, alteridade e a epidermização da inferioridade racial ${ }^{1}$
}

\section{Dandriel Henrique da Silva Borges*}

DOI: 10.11606/issn.2318-8855.v9i1p16-30

Resumo: Esse ensaio se propõe a refletir sobre temáticas históricas e sociais como a memória, a alteridade e epidermização da inferioridade racial, além do próprio racismo, pensando nas consequências delas e de outras mais em populações racializadas, no caso, indígenas e negros. Para isso, foi buscado apoio em escritos de intelectuais como Michael Pollak (1989), Frantz Fanon (2008), Valentin-Yves Mudimbe (2013) e bell hooks (2019).

Palavras-chave: Memória; Alteridade; Racismo; Michael Pollak; Frantz Fanon

* Graduando em História pela Universidade Federal do Rio de Janeiro (UFRJ). ORCID: https://orcid.org/0000-0001-8508-7114. E-mail:

1 O ensaio é derivado do trabalho final para a conclusão da disciplina de História da África Contemporânea III, ministrada do semestre letivo de 2019.2 na Universidade Federal do Rio de Janeiro (UFRJ), pela Profa Dra Mônica Lima e Souza 


\section{ensaios}

\section{Populações racializadas: um ensaio teórico sobre construção da memória coletiva,}

alteridade e a epidermização da inferioridade racial

Michael Pollak (1948-1992), sociólogo e historiador austríaco, ao dialogar com os estudos de Halbwachs e Durkheim, leciona sobre o processo de estruturação do que ele chama de memória coletiva. Um amplo conjunto de pontos de referências seriam responsáveis por estabelecer as memórias individuais das diferentes pessoas nos grupos sociais em que estão inseridas para, só então, o indivíduo (enquanto particular) se inserir perante a memória de sua coletividade. Embora não seja uma imposição, devido a uma "força quase institucional (POLLAK, 1989, p. 3)" a memória coletiva teria responsabilidade até mesmo perante o estabelecimento de coesão social, não por coerção, mas sim por uma afetividade perante um dado grupo de pessoas.

Quando falamos de uma nação, construída por entidades de grande influência em seus territórios (como as igrejas cristãs e a Forças Armadas, por exemplo, no caso brasileiro e de diversos outros países latino-americanos e de África) se configuraria algo chamado de "memória oficial (POLLAK, 1989, p. 4)". É ela que usualmente domina a memória coletiva, através da qual a massa dos indivíduos adquire seus papéis e exerce suas funções perante as instituições que compõem a sociedade onde se estabelece.

Tendo um papel tão importante perante as sociedades, a memória de uma coletividade acaba se construindo perante uma disputa de narrativas: as forças políticas e institucionais, ao elaborarem uma narrativa, idealizando uma memória tida como oficial, conduziriam à apresentação de um passado tal qual construído por elas mesmas, de modo a cumprir com seus interesses através da constituição de uma memória coletiva daquela dada sociedade que Ihes favoreça (POLLAK, 1989, p. 10). Em contrapartida, haveria também as memórias daqueles grupos mais periféricos, "minoritários", subalternizados, com divergências perante a construção da citada 


\section{ensaios}

\section{Dandriel Henrique da Silva Borges}

memória oficial. Com reivindicações próprias, esses indivíduos marginalizados buscariam romper com esse discurso vinculado pelos meios oficiais (associados ao Estado, por exemplo) através de artifícios como a construção de uma história oral. A tensão dessas disputas entre a memória oficial e aquelas que Pollak chama de “subterrâneas (1989, p. 4-5)" acabaria por fragilizar os consensos e gerar conflitos perante os distintos grupos de uma mesma sociedade. Em suas próprias palavras esse autor afirma que "uma vez que as memórias subterrâneas conseguem invadir o espaço público, reivindicações múltiplas e dificilmente previsíveis se acoplam a essa disputa da memória (POLLAK, 1989, p. 5)".

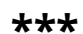

Quando pensamos nas terras hoje pertencentes oficialmente ao Estado brasileiro, dois grupos racializados ${ }^{2}$ podem ser elencados facilmente: Os negros (descendentes de africanos da diáspora) e os indígenas (povos originários desses territórios).

São dois diferentes grupos que possuem uma infinidade de variações étnicas em seu interior, por mais que o senso comum ainda teime em homogeneizar cada um deles. Seja na sala de aula da educação básica, seja na do ensino superior ou mesmo no imaginário popular, essas populações são pensadas sem muitas convergências. Fora, talvez, as opressões compartilhadas sofridas nas mãos dos invasores europeus (opressões essas muitas vezes conservadas na contemporaneidade).

\footnotetext{
${ }^{2}$ Grupos racializados aqui são entendidos enquanto populações cuja etnicidade destoa do padrão hegemônico imposto por uma visão de mundo que parte de um ponto de vista eurocêntrico, ou seja, centralizado na Europa
} 


\section{ensaios}

\section{Populações racializadas: um ensaio teórico sobre construção da memória coletiva, alteridade e a epidermização da inferioridade racial}

As resistências desses povos, menos lembradas do que deveriam, são marcadas pela perpetuação de suas tradições por vias orais -- o que, numa sociedade cuja memória oficial se construiu através de documentos escritos, jogou durante séculos muito da história das pessoas que compõem esses grupos racializados para o "subterrâneo".

Nos últimos anos, aspectos das memórias de povos indígenas e africanos da diáspora começaram a "emergir" para discussões em sala de aula (e fora também). Não por interesse de visões eurocêntricas que ainda guiam boa parte da educação brasileira (e do Estado e suas políticas como um todo), mas como resultado de lutas sociais realizadas por essas minorias sociais.

A aprovação das Leis $n^{\circ} 10.639$ de $2003^{3}$ e $n^{\circ} 11.645$ de $2008^{4}$ é exemplo de resultado e caminho de lutas das populações negras e indígenas. A partir do momento que as histórias desses povos deixam de ser restritas a uma "memória subterrânea" e passam então a serem discutidas obrigatoriamente em sala de aula (mesmo que nem sempre do melhor modo), é provocada toda uma disputa de narrativas sobre o passado nacional (MARTINS, 2009, p. 161-166; SANTOS, 2010, p. 59-61; BITTENCOURT, 2012, p. 101-106), essencial para a elaboração de uma identidade desses povos (MARTINS, 2009, p. 153-159).

\footnotetext{
${ }^{3}$ Inclui no currículo oficial da Rede de Ensino a obrigatoriedade da temática "História e Cultura AfroBrasileira" (BRASIL, 2003).

${ }^{4}$ Inclui no currículo oficial da rede de ensino a obrigatoriedade da temática "História e Cultura AfroBrasileira e Indígena" (BRASIL, 2008).
} 


\section{ensaios}

\section{Dandriel Henrique da Silva Borges}

Embora esse ensaio não trate especificamente da questão da educação, esse é um aspecto a ser elencado por dois motivos: 1) Ser um exemplo didático e contemporâneo sobre a disputa de memórias; 2) É resultado de uma luta, ainda não finalizada, mas que segue persistente e é um retrato da resistência das populações racializadas.

Quando ousamos trabalhar com questões raciais (seja envolvendo os povos da diáspora ou as comunidades indígenas), é necessário sempre tomar o máximo cuidado para não tratar essas pessoas enquanto vítimas. Por mais que tenhamos sido ensinados a isso e por vezes propaguemos esse discurso mesmo de modo não intencional, não podemos perder do nosso horizonte ("de expectativa"5, como diria Koselleck) a ciência de que não há como escrever ou lecionar sobre uma história desses povos sem tratar das suas lutas e das suas resistências. Essas populações não são definidas pelas opressões que sofreram (e ainda sofrem), mas suas histórias e, mais do que isso, suas identidades são intrinsecamente ligadas às suas lutas e resistências.

Como já dissemos antes, não vamos nos concentrar na educação; também não nos estenderemos na resistência. O foco aqui serão reflexões teóricas que permeiam a construção da memória, da alteridade $^{6}$ e da interiorização da inferiorização racial, conceitos a serem melhor desenvolvidos no decorrer deste trabalho. Ainda assim, será aqui repetido uma vez mais: não há como falar de populações racializadas sem trazer, mesmo que só pincelando (como foi tentado aqui), a existência de lutas e de

\footnotetext{
${ }^{5} \mathrm{O}$ "horizonte de expectativas" aqui é entendido como um cenário que, embora nunca consigamos alcança-lo, nos direciona. As expectativas que guiam esse horizonte nunca realizado têm sempre a potência da mudança. A própria inalcançabilidade é o que permite essa metamorfose. Para uma discussão mais aprofundada sobre esse conceito ver: KOSELLECK, 2006.

${ }^{6}$ A alteridade diz respeito a relação entre seres humanos, onde um vê o segundo como "o outro", diferente de si.
} 


\section{ensaios}

Populações racializadas: um ensaio teórico sobre construção da memória coletiva, alteridade e a epidermização da inferioridade racial

resistências.

Em seu clássico, Pele Negra, Máscaras Brancas, Frantz Fanon (1925-1961), nascido na Martinica, psiquiatra, filósofo e revolucionário que participou da luta pela independência da Argélia, partindo das consequências do contato dos europeus com diferentes povos originários de África e da América Central, mas gerando uma obra cuja narrativa não se restringiu aos "sujeitos negros" ilustrando, de modo mais amplo, “a profundidade da colonialidade como um problema (MALDONADO-TORRES, 2018, p. 45)", argumenta sobre a construção de uma alteridade que ajudou a construir uma submissão dos povos agredidos perante as narrativas "oficiais" defendidas pelos europeus (FANON, 2008, p. 33-34).

Tendo ciência de que "falar é existir (FANON, 2008, p. 33)" e que a história difundida oralmente é um dos principais instrumentos de popularização dos discursos que compõem a "memória subterrânea (POLLAK, 1989, p. 4-5)", além de ser também um instrumento essencial ao se pensar temas relacionados à história de África, como Joseph Ki-Zerbo (1922-2006), político e historiador de Burkina Faso, defendeu em 1981, na introdução da famosa coleção intitulada História Geral da África (KI-ZERBO, 2010, XXXIV, XXXVIII-XLII), começamos a compreender o papel da tradição oral ao direcionar o objeto de pesquisa a algum território, tempo ou indivíduo/coletivo derivado do continente mãe. Indo um pouco mais além, como pesquisadores brasileiros já defendem há décadas, os testemunhos orais são instrumentos plurais que não deve ser ignorados também em pesquisas de certos recortes da própria história do Brasil (ALBERTI, 2004; FERREIRA, AMADO, 2006; ALBERTI, 2013), mesmo quando não 


\section{ensaios}

\section{Dandriel Henrique da Silva Borges}

diretamente ligada à África.

Fanon defende que o próprio ato de se comunicar, por si só, já adquire toda uma importância social. Quanto mais um indivíduo de algum dos territórios colonizados pelos "homens brancos" se portar, agir e falar, aceitar e adentrar o que se defende como valores ditos "civilizados", por se adequarem a uma narrativa que contribuiria para a construção de uma memória oficial de agrado dos europeus, mais submisso o indivíduo dessa sociedade dominada será. Em contrapartida, será mais aceito, não só pelos indivíduos que também tiveram suas identidades subjugadas, mas também pelos próprios dominadores, visto que "quanto mais assimilar os valores culturais da metrópole, mais o colonizado escapará de sua selva (FANON, 2008, p. 34)" -- sendo a "selva" a síntese dos estereótipos racistas perpetuados em relação às diversas culturas africanas, cujas tradições tanto destoavam daqueles valores impostos por indivíduos que invadiram, usurparam e violentaram suas terras e corpos. Como lembra Ki-Zerbo, numa visão baseada na alteridade, “o ‘outro"' é sempre visto como "atrasado, bárbaro, selvagem em diversos graus" por ser "sempre diferente (2010, XLIX, grifo nosso)" daqueles advindos das culturas que lhes foram impostas por aqueles que os julgam.

Nessas relações, os valores defendidos pela narrativa oficial europeia apareceriam disfarçados de um ideal civilizatório.Deste modo, a cultura e identidade dos povos originários e dos advindos da diáspora africana, que foram construídas enquanto um discurso dissidente perante uma constante disputa de memórias naquelas sociedades que passavam (e ainda passam) por uma disputa de memória, são tratadas como algo "selvagem" (FANON, 2008, p. 42), que se distancia de um ideal de humanidade então derivado do "homem branco" e europeu, cujas instituições controlavam as narrativas que compunham a "memória oficial", perante a qual eram subjugados os indivíduos dos povos por eles colonizados. 


\section{ensaios}

\section{Populações racializadas: um ensaio teórico sobre construção da memória coletiva,}

alteridade e a epidermização da inferioridade racial

Esse "projeto colonizador (MUDIMBE, 2013 p. 19)", como nomeado por ValentinYves Mudimbe (1941-), filósofo, professor e escritor congolês, chocou-se com os valores tradicionais e espirituais daquelas sociedades, de modo a banalizar os mesmos. Isso contribuiu para uma fragmentação cultural do colonizado e legitimou o domínio cultural daquele que se descreve enquanto civilizado, perante aquele que é tanto afirmado quanto imposto enquanto um "selvagem", o qual intrinsecamente absorve essa construção narrativa de colonizadores europeus. Isso gera o que Fanon nomeia de "epidermização dessa inferioridade (FANON, 2008, p. 28)", desse racismo, que ocorre quando os próprios indivíduos ditos colonizados naturalizam e reproduzem a inferiorização que Ihes foi imposta. Essa seria então uma das consequências da concepção de alteridade, também trabalhada por esse autor, a qual cada vez mais alimenta a ideia do "outro", "selvagem", enquanto um ser distante de um ideal de ser humano, tal qual concebida pelas narrativas que compõem a memória oficial difundida e estruturada pelas instituições dos Estados europeus.

De modo parecido a esse autor, pensando em instrumentos de perpetuação dessa inferiorização racial, bell hooks (1952-), escritora, teórica feminista, artista e ativista social estadunidense, aborda o "racismo internalizado". Segundo ela, as imagens às quais as pessoas estão expostas são efetivos instrumentos de perpetuação de padrões idealizados (baseados em ideais europeus), de uma lógica que reforça uma ótica que privilegia o que nomeia de "supremacia branca", reforçada, conscientemente ou não, não apenas pelas pessoas brancas, mas também por aqueles não brancos que "vejam o mundo pelas lentes da supremacia branca (2019, p. 32)". Essas imagens perpetuadas pela própria cultura pop (em livros, filmes, séries, etc) que muitas vezes reforçam estereótipos, afetam o modo como as pessoas se veem, assim sendo, o 


\section{ensaios}

\section{Dandriel Henrique da Silva Borges}

controle sobre as próprias imagens reflete um controle sobre os indivíduos representados.

O processo para romper com essa lógica racista vai além da simples alteração das imagens, necessita de uma mudança de paradigmas, da perspectiva e do modo como essas imagens são vistas. Minorias são ensinadas a aceitar e apreciar imagens que as depreciem. bell hooks defende que para romper com essa política de dominação são necessárias algumas atitudes, como a inclusão de aliados que não necessariamente sejam pessoas racializadas e, principalmente, a necessidade de serem desenvolvidas atitudes revolucionárias, atitudes críticas, que provoquem e engajem, para só então romper com os padrões racistas (2019, p. 33-41).

No que tange à relação dos europeus com os diversos povos racializados, espalhados por diferentes continentes, o tal projeto colonizador construiu legitimidade agindo pelas mais diferentes frentes:

No caso específico da discriminação racial que favoreceu o europeu e atingiu todos os demais povos do mundo, o racismo não foi apenas um resultado da falta de conhecimento, de discernimento, de solidariedade, ele não foi apenas a falta de algo, foi uma presença, uma positividade, teve um cunho científico e jurídico, informou doutrinas eruditas, enaltecidas pelo prestígio da ciência (SILVEIRA, 1999, p. 88-89, grifos nossos).

Buscando a legitimidade de novas instituições que iam ganhando importância, como as científicas, o discurso cada vez mais hegemônico, que supervalorizava a cultura e as tradições europeias, foi construído também na forma de um racismo científico e jurídico legitimado pelas instituições de poder que ascendiam. “Resultado de um trabalho sistemático de numerosos especialistas a serviço de (ou afinados com) uma política de conquista e subordinação (SILVEIRA, 1999, p. 90)" e se apoiando nas elites intelectuais, a já citada epidermização da inferioridade era reforçada de modo a 


\section{ensaios}

Populações racializadas: um ensaio teórico sobre construção da memória coletiva, alteridade e a epidermização da inferioridade racial

contribuir para o estabelecimento de uma estruturação do racismo enquanto uma hegemonia global.

A negação da humanidade do "outro" reforçava um discurso baseado numa lógica de alteridade, onde quanto mais "selvagens", ou seja, quanto menos abandonassem suas culturas e tradições para se submeterem aos ideais europeus, mais seriam vistos como inimigos desses valores impostos pelo chamado "projeto colonizador (MUDIMBE, 2013 p. 19)", cada vez mais embasado pelas instituições que construíam e legitimavam o poder do "homem branco", o europeu "civilizado". Esse mesmo discurso culmina na "banalização de todo o modo de vida tradicional e da estrutura espiritual (MUDIMBE, 2013 p. 19)" desses povos, o que acarreta na marginalização e no silenciamento dos mesmos, contribuindo para o afastamento de suas narrativas perante o que Pollak chamou de uma "memória oficial", Ihes restando a chamada "memória subterrânea (1989, p. 4-5)".

Tomando como verdade a narrativa que embasava um projeto colonizador e a consequente construção de uma memória oficial que thes favorecesse, pelos colonizadores, eram silenciados cada vez mais aqueles que tiveram suas terras, seus corpos e suas tradições subjugadas. Foi construído então, a nível global, um processo que culminou numa memória coletiva que legitimou (e de certo modo ainda legitima) uma supremacia ocidental, branca e europeia. Quanto mais o "outro" desse padrão destoasse, menos "civilizado" e mais "selvagem" era considerado. Em outras palavras, menos era então legitimada sua própria humanidade. 


\section{ensaios}

\section{Dandriel Henrique da Silva Borges}

O processo de estruturalização do racismo a nível global funcionou de tal modo que a inferiorização das características ligadas às populações racializadas dominadas foi internalizada tão profundamente dentro das próprias instituições das sociedades das quais fazem parte que, mesmo sem o domínio direto dos povos europeus tal qual séculos atrás, ela segue preservada nas sociedades em pleno século XXI.

O racismo, seja contra indígenas, seja contra negros, segue estruturalizado ao nível global e internalizado ao individual. Segue preso num pensamento cuja alteridade está no âmago de sua formação (tão influenciado por uma educação que só tão recentemente teve alguns de seus aspectos reformulados), segue quando a memória coletiva apagou o passado de seu povo e assim também a própria identidade desses indivíduos.

Segue quando a intolerância religiosa faz pessoas verem o diferente enquanto algo indigno de respeito e destroem terreiros de religiões de matriz africana (JANSEN, 2019).

Segue quando o Cacique Francisco Pereira, Tukano, é assassinado na frente da sua família (MARQUES, 2019).

Segue quando, no dia anterior a quando estou escrevendo essas linhas, nove jovens, em sua maioria negros e periféricos, são mortos pisoteados devido a uma ação truculenta da polícia militar de São Paulo em um baile funk na favela de Paraisópolis (RODRIGUES, BARROS, 2019; HENRIQUE, 2019).

Essas ações seguem recortes. Nem todos estamos submetidos às mesmas condições nessa sociedade em que vivemos.

Destoar do padrão imposto por aqueles que invadiram essas terras há séculos 
Populações racializadas: um ensaio teórico sobre construção da memória coletiva, alteridade e a epidermização da inferioridade racial

tem um peso.

Um peso que muitas vezes mata.

Mata o indígena, mata o negro, mata o pobre, mata a mulher, mata o LGBT+, mata o "diferente".

Mata pais, mães, filhos, filhas, tios, tias, sobrinhos, sobrinhas, mata famílias.

Mata pessoas que não são números!

Elas têm rostos, histórias, planos, objetivos, sonhos e esperanças!

O racismo segue enquanto um projeto genocida que mata o futuro.

\section{Referências bibliográficas}

ALBERTI, Verena. Ouvir contar: textos em história oral. Rio de Janeiro: FGV Editora, 2004.

ALBERTI, Verena. Manual de história oral. Rio de Janeiro: FGV Editora, 2013.

BITTENCOURT, Circe. História das populações indígenas na escola: memórias e esquecimentos. In: PEREIRA, Amílcar; MONTEIRO, Ana Maria. Ensino de História e culturas afro-brasileiras e indígenas. Rio de Janeiro: Pallas, 2012.

BRASIL. Presidência da República. Lei no 10.639, de 9 de janeiro de 2003. Altera a Lei no 9.394, de 20 de dezembro de 1996, que estabelece as diretrizes e bases da educação nacional, para incluir no currículo oficial da rede de ensino a obrigatoriedade da temática "História e Cultura Afro-Brasileira", e dá outras providências. Brasília, 2003.

BRASIL. Presidência da República. Lei n 11.645, de 10 de março de 2008. Altera a Lei no 9.394, de 20 de dezembro de 1996, modificada pela Lei $n^{\circ}$ 10.639, de 9 de janeiro de 2003, que estabelece as diretrizes e bases da educação nacional, para incluir no currículo oficial da rede de ensino a obrigatoriedade da temática "História e Cultura Afro-Brasileira e Indígena". Brasília, 2008. 


\section{Dandriel Henrique da Silva Borges}

FANON, Frantz. Pele negra máscaras brancas. Salvador: Editora da Universidade Federal da Bahia, 2008. Disponível em: https://www.geledes.org.br/wpcontent/uploads/2014/05/Frantz_Fanon_Pele_negra_mascaras_brancas.pdf. Acessado em 02/12/2019.

FERREIRA, Marieta; AMADO, Janaina. Usos e abusos da história oral. Rio de Janeiro: FGV Editora, 2006.

HENRIQUE, Alfredo. Veja quem são os jovens mortos em Paraisópolis. Folha de São Paulo, online, 2 dez. 2019. Disponível em: https://agora.folha.uol.com.br/sao-paulo/2019/12/vejaquem-sao-os-jovens-mortos-em-paraisopolis.shtml. Acessado em 02/12/2019.

HOOKS, bell. Olhares negros: raça e representação. Rio de Janeiro: Elefante editora, 2019.

JANSEN, Roberta. Traficantes evangélicos causam terror a religiões africanas. Terra, online, 19 ago. 2019. Disponível em: https://www.terra.com.br/noticias/brasil/cidades/traficantesevangelicos-causam-terror-a-religioes-

africanas,1780cd9c3e66e3685264918be080ac4db4ddw64t.html. Acessado em 02/12/2019.

KI-ZERBO, Joseph. Introdução Geral. In: História Geral da África, V.1, XXXI-LVII, 2010.

KOSELLECK, Reinhart. Futuro Passado: contribuição à semântica dos tempos históricos. Rio de Janeiro: Contraponto/Editora PUC Rio, 2006.

MALDONADO-TORRES, Nelson. Analítica da colonialidade e da decolonialidade: algumas dimensões básicas. In: BERNARDINO-COSTA, Joaze, et. al. Decolonialidade e pensamento afrodiaspórico. 2 ed. Belo Horizonte: Autêntica Editora, 2018, p. 27-53.

MARQUES, Patrick. Cacique da etnia Tukano é morto a tiros na frente da família, em Manaus. G1, online, 27 fev. $2019 . \quad$ Disponível em: https://g1.globo.com/am/amazonas/noticia/2019/02/27/cacique-da-etnia-tukano-e-morto-atiros-em-frente-a-familia-em-manaus.ghtml. Acessado em 02/12/2019.

MARTINS, Maria. As sociedades indígenas, a história e a escola. Antíteses, v. 2, n. 3, p. 153-167, 2009.

MUDIMBE, V. Y. A invenção de África: gnose, filosofia e a ordem do conhecimento. Mangualde (Portugal), Luanda: Edições Pedago; Edições Mulemba, 2013.

POLLAK, Michael. Memória, Esquecimento, Silêncio. Estudos Históricos, Rio de Janeiro, v. 2, n. 3, p. 3-15, 1989. 


\section{ensaios}

Populações racializadas: um ensaio teórico sobre construção da memória coletiva, alteridade e a epidermização da inferioridade racial

RODRIGUES, Artur; BARROS, Laíssa. Nove pessoas morrem pisoteadas em baile funk de Paraisópolis. Folha de São Paulo, online, 1 dez. 2019. Disponível em: https://www1.folha.uol.com.br/cotidiano/2019/12/oito-pessoas-morrem-pisoteadas-em-bailefunk-de-paraisopolis-diz-policia.shtml. Acessado em 02/12/2019.

SANTOS, Lorene. Ensino de História e a Lei 10.639/03: diálogos entre campos de conhecimento, diretrizes curriculares e os desafios da prática. Cadernos de História, Belo Horizonte, v. 12, n. 17, p. 59-92, 2011.

SILVEIRA, Renato. Os selvagens e a massa: papel do racismo científico na montagem da hegemonia ocidental. Afro-Ásia. n. 23, p. 87-144, 1999. 